\title{
Spatial Distribution Pattern and Interspecific Association Analysis of Thuja koraiensis Population
}

\author{
Ying Zhao, Hui Jin*, Liya Huang, Qinghong Chen, Lijie Liu, Yuhong Dai, Hang Yin, Xiang Jia, Chao Wang \\ Jilin Provincial Joint Key Laboratory of Changbai Mountain Biocoenosis and Biodiversity, \\ Changbaishan Academy of Science, Yanbian133613, Jilin, China
}

\begin{abstract}
In this paper, the methods such as Clumping index, Aggregate index, CASSIE index, Diffusion coefficient $C, K$ index in negative binomial distribution and $m^{*}-m$ wao regression, Taylor power law were used to analyze the spatial distribution pattern of Thuja koraiensis community. The results showed that the spatial distribution pattern of Thuja koraiensis community presented significantly aggregate distribution. Based on $2 \times 2$ contingency table, interspecific association analysis was conducted by means of Variance ratio method, $\chi^{2 \text {-test }}$, Association coefficient, together with point correlation coefficient, The overall relevance of pure forest community where Thuja koraiensis population were distributed and scattered forest of Thuja koraiensis community both showed negative correlation. In the pure forest community, Thuja koraiensis was extremely significantly negatively correlated with Sorbus pohuashanensis $(\mathrm{p}<0.01)$, and positively correlated with other shrub species, but did not reach a significant level. In the scattered forest community, Thuja koraiensis was positively correlated with Euonymus rehderianus, Lonicera edulis, Rubus sachalinensis, Acer tegmentosum, and negatively correlated with other species. Studies suggest that protecting species which are positively correlated with Thuja koraiensis to form an environment conducive to the survival of specific species together has certain guiding significance for the protection and utilization of Thuja koraiensis community.
\end{abstract}

\section{Introduction}

Spatial pattern analysis of populations is an important method to study population characteristics, interaction between populations and the relationship between population and environment and also one of the hot spots of ecological research[1]. The spatial distribution pattern of population and its changing trend are the main factors that influence the development of the number of population, the ecological and biological characteristics of the dominant population and its occurrence and development dynamics have a vital impact on the appearance, structure and succession direction of the community[2]. Interspecific association or species association refers to the spatial interconnectedness of different species, which is the basis of community formation and evolution[3, 4]. The study of interspecific association of the community can effectively reflect the distribution of each species in the community, as well as the degree of adaptation of each species to environmental factors and the interspecific correlation of species under specific environmental factors, which will help to further identify the community structure, type and community succession trend, etc[5]. At present, the researches mainly focus on ecological characteristics[6], growth rules[7, 8] and breeding experiments[9, 10] at home and abroad, while there is no report on interspecific association of Thuja koraiensis community.
Thuja koraiensis, an evergreen arbor of Cupressaceae is the second class national protected plant and endangered ENA2c. The natural distribution of Thuja koraiensis is narrow, which is mainly distributed at the altitude of $600-2000 \mathrm{~m}$ in Changbai Mountain Nature Reserve. In recent years, due to deforestation and habitat destruction, the distribution range is gradually reduced, and the Thuja koraiensis population is less and less, almost endangered. Thuja plants have the functions of requiem, detoxifying, beauty, anti-inflammation and detoxification. They are relict plants from the Cretaceous Period in the age of the Dinosaurs, the world's rare "livin $\mathrm{g}$ fossil", which are of significant value to study ancient geology and paleontology.

Therefore, the study of spatial distribution pattern and interspecific association of Thuja koraiensis not only reflects the structure characteristics and interspecific relationship of Thuja koraiensis population, but also helps to reveal the stability and succession mechanism of Thuja koraiensis population, which provides certain support for the breeding and protection of Thuja koraiensis.

\section{Research Area and Research Method}

\subsection{Natural environment}

\footnotetext{
$\overline{\text { * Corresponding author:fivecl10jinhui@ } @ 163 . c o m ~}$
} 
The research area is located in Changbai Mountain Nature Reserve, Jilin, China. The zonal climate of this area belongs to the continental mountain climate with monsoon influence. It is cold and dry in winter; warm and moist in summer. Precipitation is mostly concentrated in July and August. The annual average temperature is $4.4{ }^{\circ} \mathrm{C}$, with extreme maximum temperature of $37.5{ }^{\circ} \mathrm{C}$ and extreme minimum temperature of $-40{ }^{\circ} \mathrm{C}$. The annual precipitation is 600 $1340 \mathrm{~mm}$, and the relative humidity is above $70 \%$, with a frost-free period of 90-100 days. The pure forest of Thuja koraiensis is distributed in the vicinity of Wushigang, which is located at the altitude of about $1853 \mathrm{~m}$ in the southern slope of Changbai Mountain. The soil is mountain dark brown forest soil, which is poor and granular light loam, and most of the rest are

Table.1 Community habitat and vegetation status in survey area

\begin{tabular}{|c|c|c|c|c|}
\hline $\begin{array}{l}\text { forest } \\
\text { type }\end{array}$ & $\begin{array}{c}\text { Altitude/ } \\
\mathrm{m}\end{array}$ & geographic coordinates & $\begin{array}{c}\text { crown } \\
\text { density } / \%\end{array}$ & dominant species of Arbor layer \\
\hline $\mathrm{P} 1$ & 1476 & $\mathrm{~N} 41^{\circ} 46^{\prime} 00.07^{\prime \prime} \mathrm{E} 128^{\circ} 04^{\prime} 34.24^{\prime \prime}$ & 85 & Thuja koraiensis, 、 Abies nephrolepis \\
\hline $\mathrm{P} 2$ & 1512 & $\mathrm{~N} 41^{\circ} 42^{\prime} 40.75^{\prime \prime}$ E $127^{\circ} 54^{\prime} 02.38$ & 70 & $\begin{array}{l}\text { Abies nephrolepis } \\
\text { Sorbus pohuashanensis 、Acer barbinerve、 } \\
\text { Acer tegmentosum 、Acer mono、 Picea } \\
\text { jezoensis var. microsperma、Betula ermanii }\end{array}$ \\
\hline P3 & 1520 & $\mathrm{~N} 41^{\circ} 44^{\prime} 40.43^{\prime \prime} \mathrm{E} 127^{\circ} 55^{\prime} 44.58^{\prime \prime}$ & 75 & $\begin{array}{c}\text { Abies nephrolepis、Acer ukurunduense、 } \\
\text { Sorbus pohuashanensis、Picea jezoensis } \\
\text { var. microsperma、Betula ermanii }\end{array}$ \\
\hline P4 & 1853 & $\mathrm{~N} 41^{\circ} 43^{\prime} 10.03^{\prime \prime} \mathrm{E} 127^{\circ} 54^{\prime} 47.33^{\prime \prime}$ & 5 & Betula ermanii, Sorbus pohuashanensis \\
\hline
\end{tabular}

\subsubsection{Data processing}

Based on the preliminary classification and careful disposal of the raw data from field surveys, the spatial distribution pattern and interspecific association of the main shrub populations were counted.

\subsubsection{Spatial distribution pattern of Population}

The following aggregate intensity indices were selected to decide the degree of difference in geographical distribution density of individuals[ $11,12,13]$.

(1) Clumping index

$$
I=S^{2} / x^{2}-1
$$

When $I<0$, it is uniform distribution, when $I=0$, it is random distribution, when $I>0$, it is aggregate distribution.

(2) $m^{*} / m$ index (Aggregate index)

On the basis of Moore's $m^{*}$ index, Lloyd proposed the $m^{*} / m$ index, that is the ratio between the average crowding degree and the average value, namely:

$$
m^{*} / m=\frac{m^{*}}{x}
$$

When $m^{*} / m<1$, it is uniform distribution, when $m^{*} / m=1$, it is random distribution, when $m^{*} / m>1$, it is aggregate distribution. distributed in the mixed community of spruce-fir and Thuja koraiensis.

\subsection{Research method}

\subsubsection{Sample plot setting and data collection}

In 2015 , one sample plot of $30 \mathrm{~m} \times 30 \mathrm{~m}$ was set up in the pure forest of Thuja koraiensis, three sample plots of $30 \mathrm{~m} \times 30 \mathrm{~m}$ were set up in scattered forest of Thuja koraiensis in Changbai Mountain Nature Reserve. The species, crown width, coverage and DBH of woody plants with $\mathrm{DBH} \geq 1.3 \mathrm{~cm}$ were investigated and recorded in detail. The sample area is summarized in Table 1.
(3) Cassie index

$$
C_{A}=\left(S^{2} / \bar{x}-1\right) / \bar{x}
$$

When $C_{A}<0$, it is uniform distribution, when $C_{A}=0$, it is random distribution, when $C_{A}>0$, it is aggregate distribution.

(4) Diffusion coefficient $C$

The index of $C=S^{2} / \bar{x}$ is used to check whether the population deviates from the stochastic pattern. When $C<1$, it is uniform distribution, when $C=1$, it is random distribution, when $C>1$, it is aggregate distribution.

(5) $K$ index in negative binomial distribution

$$
K=x^{2} /\left(S^{2}-x\right)
$$

In negative binomial distribution, When $K<0$, it is uniform distribution, when $K \rightarrow+\infty$, it is random distribution, when $K>0$, it is aggregate distribution.

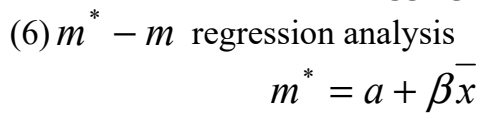

It is used to study the correlation between $m^{*}$ and the mean value. In the formula, $a$ is the average crowding degree of the basic components which are distributed by size: When $a=0$, the basic component of the distribution is a single individual; When $a>0$, individuals are attracted to each other, and the basic components of distribution are divided into individual 
groups; When $a<0$, individuals repel each other. $\beta$ is the spatial distribution diagram of the basic components: When $\beta<1$, it is uniform distribution, when $\beta=1$, it is random distribution, when $\beta>1$, it is aggregate distribution.

(7)Taylor's power law model

$$
\begin{gathered}
\lg S^{2}=\lg a+b \lg \bar{x} \\
S^{2}=a \bar{x}
\end{gathered}
$$

That is power function relationship. When $b \rightarrow 0$, it is uniform distribution, when $b=1$, it is random distribution, when $b>1$, it is aggregate distribution.

\subsubsection{Overall Association Analysis}

The correlation between multiple species was simultaneously determined by the variance ratio method (VR), and statistics W was used to test the correlation between multiple species. The calculation formula could be found in the References[14,15].

\subsubsection{Interspecific Association Analysis}

Based on $2 \times 2$ contingency table, the a, b, c, and $d$ values of various species pairs were calculated. A comprehensive analysis of the nature and degree of species pair association were made using the Yates correction coefficient formula based on chi-square test, combined with the point correlation coefficient (PCC), association coefficient (AC) and other measurement indicators. Please refer to $[14,15]$ for specific method.

\section{Results and Analysis}

\subsection{Spatial Distribution Pattern of Population}

According to the data of 4 sample plots, the aggregate index above was measured. As can be seen from the table, the spatial distribution pattern of Thuja koraiensis population presented aggregate distribution. Among them, the diffusion coefficient was all greater than 1, after comparing the difference significance between $t$ and $\mathrm{t} 0.05$, it was determined that both reached the significant difference level. According to the mean crowding $M^{*}$ index, the maximum crowding of Thuja koraiensis in P4 pure forest was 39.813 , followed by P1, P3 and P2 sample plots.

Table 2. The aggregate index of spatial distribution of Thuja koraiensis

\begin{tabular}{ccccccccc}
\hline $\begin{array}{c}\text { population } \\
\text { number }\end{array}$ & $\bar{x}$ & $S^{2}$ & $\begin{array}{c}\text { Diffusion } \\
\text { coefficient C }\end{array}$ & I index & $\begin{array}{c}\text { Mean } \\
\text { crowding } M^{*}\end{array}$ & $M^{*} / \bar{x}$ index & $\begin{array}{c}\text { CA } \\
\text { index }\end{array}$ & $\begin{array}{c}\text { distribution } \\
\text { pattern }\end{array}$ \\
\hline P1 & 6.58 & 61.62 & $9.365^{* *}$ & 8.365 & 14.945 & 2.271 & 1.271 & $\mathrm{C}$ \\
P2 & 0.14 & 0.69 & $4.929^{* *}$ & 3.929 & 4.069 & 29.061 & 28.061 & $\mathrm{C}$ \\
P3 & 4.86 & 28.98 & $5.963^{* *}$ & 4.963 & 9.823 & 2.021 & 1.021 & $\mathrm{C}$ \\
P4 & 37.72 & 124.03 & $3.616^{* *}$ & 2.616 & 40.336 & 1.069 & 0.069 & $\mathrm{C}$ \\
\hline
\end{tabular}

Note: C: Cluster distribution

From several aggregate indices measured, each index value was in accordance with the normal distribution of Thuja koraiensis population, presenting an aggregate fracture distribution state in both pure forest and scattered forest.

In order to reflect more accurately the spatial pattern type of Thuja koraiensis natural population in different habitats, a further $M^{*} / \bar{x}$ regression analysis was carried out on the data of four sample plots. The regression equation is: $M^{*}=5.89774+0.92458 \bar{x}$, $\mathrm{R}=0.9914$.

In the regression relation, $\alpha$ is $5.898, \beta \approx 1$, indicating the population is in a state of aggregate distribution. By Taylor power law statistical approaches, regression is performed on the logarithm between mean and variance of the sample. The regression equation is:

$$
\lg S^{2}=0.75905+0.98282^{*} \lg \bar{x}, \mathrm{R}=0.9856
$$

which further confirmed the aggregate distribution of Thuja koraiensis population.

\subsection{Interspecific Association}

\subsubsection{Community Overall Association}

The multi-species interspecific association coefficient of the pure forest community of Thuja koraiensis, population was $\mathrm{VR}=0.4906$, indicating that there was a negative correlation between species in general. Using the statistics $\mathrm{W}$ to detect the degree to which the VR value deviated from $1, \mathrm{~W}=7.1628$ was obtained. From the table, we knew $x_{0.05}^{2}(36)=23.269$, $x_{0.95}^{2}(36)=50.998$, and $\mathrm{W}$ was not in the range (23.269, 50.998), indicating there was significant negative correlation of the overall association between species. The multi-species interspecific association coefficient of scattered community of Thuja koraiensis was $\mathrm{VR}=0.666$, indicating that there was a negative correlation between species. Using the statistics W to detect the degree to which the VR value deviated from 1 , it was found that $\mathrm{W}=23.979$. from the table,we knew $\mathrm{W}$ 
was in the range $(23.269,50.998)$. There was no significant negative correlation of the overall association between species.(Table 3\&4)

Table 3. Overall association analysis between species in the pure forest community of Thuja koraiensis

\begin{tabular}{ccccccc}
\hline Coefficient $\mathrm{t}$ & $\sigma_{\mathrm{T}}{ }^{2}$ & $\mathrm{~S}_{\mathrm{T}}{ }^{2}$ & $\mathrm{VR}$ & $\mathrm{W}$ & $\begin{array}{c}\chi^{2} \text { Threshold } \\
\left(\chi^{2}{ }_{0.05}(\mathrm{~N}), \chi^{2}{ }_{0.95}(\mathrm{~N})\right)\end{array}$ & Overall association \\
\hline Measure value & 0.7303 & 0.3583 & 0.4906 & 7.1628 & $(23.269,50.998)$ & $\begin{array}{c}\text { significant negative } \\
\text { correlation }\end{array}$ \\
\hline
\end{tabular}

Table 4. Overall association analysis between species in the scattered forest community of Thuja koraiensis

\begin{tabular}{ccccccc}
\hline Coefficient $\mathrm{t}$ & $\sigma_{\mathrm{T}}{ }^{2}$ & $\mathrm{ST}^{2}$ & $\mathrm{VR}$ & $\mathrm{W}$ & $\begin{array}{c}\chi^{2} \text { Threshold } \\
\left(\chi^{2}{ }_{0.05}(\mathrm{~N}), \chi^{2}{ }_{0.95}(\mathrm{~N})\right)\end{array}$ & Overall association \\
\hline Measure value & 2.413 & 1.321 & 0.666 & 23.979 & $(23.269,50.998)$ & $\begin{array}{c}\text { No significant } \\
\text { negative correlation }\end{array}$ \\
\hline
\end{tabular}

\subsubsection{Interspecific Association Analysis}

3.2.2.1 The association between species-pairs in pure forest community of Thuja koraiensis
The association measure between pure forest community of Thuja koraiensis and shrub species was recorded in Table 5.

Table 5. Association measure value of Thuja koraiensis and main arbor species in pure forest community

\begin{tabular}{cccccc}
\hline Main shrub species & AC & $\begin{array}{c}\text { Adjustment } \\
\chi^{2} \text { value }\end{array}$ & PCC & $\begin{array}{c}\text { Fisher Accurate } \\
\text { testing of two- } \\
\text { tailed P-value }\end{array}$ & $\begin{array}{c}\text { significance of } \\
\text { difference }\end{array}$ \\
\hline Sorbus pohuashanensis & -1.000 & 2.7309 & -1.000 & 0.000 & $* *$ \\
Rosa marretii & 1.000 & 2.7309 & 0.0833 & 0.764 \\
Lonicera caerulea var. edulis & 1.000 & 2.7309 & 0.0833 & 0.764 \\
Syringa wolfii & 1.000 & 2.7309 & 0.0833 & 0.764 \\
Oplopanax elatus & 1.000 & 0.9972 & 0.1231 & 0.657 \\
Acer barbinerve & 1.000 & 2.7309 & 0.0833 & 0.764 \\
Corylus mandshurica & 1.000 & 2.7309 & 0.0833 & 0.764 \\
\hline
\end{tabular}

Both AC and PCC were used to describe the degree of association between species, which had high similarities. In the pure forest community, Thuja koraiensis was extremely significantly negatively correlated with Sorbus pohuashanensis $(p<0.01)$, and positively correlated with other shrub species, but did not reach a significant level.

3.2.2.2 The association between species-pairs in the scattered forest community of Thuja koraiensis

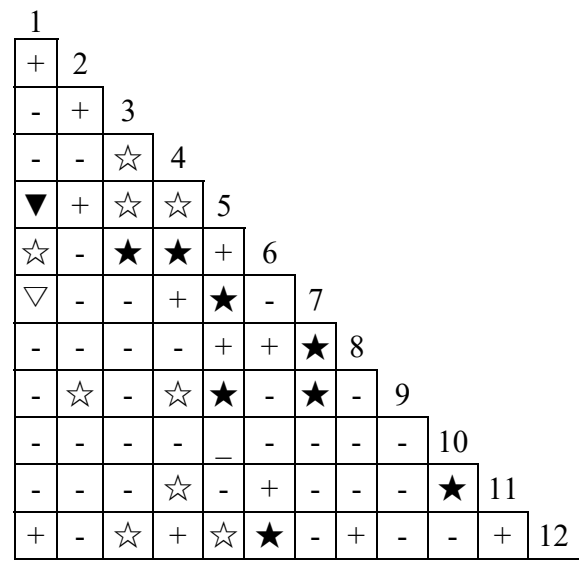




\begin{tabular}{|c|c|c|c|c|c|c|c|c|c|c|c|c|}
\hline - & - & - & & $\hat{\tau}$ & $\star$ & - & - & - & - & - & + & 13 \\
\hline+ & - & - & - & - & $\hat{n}$ & - & - & + & - & - & $\star$ & - \\
\hline
\end{tabular}

Fig1. $\chi^{2}$ Test semi-matrix figure

Note: + Insignificant positive correlation, Insignificant negative correlation,

is Significant positive correlation $(p<0.05)$, $\star$ Extremely significant positive correlation $(p<0.01)$,

$\nabla$ Significant negative correlation $(p<0.05)$,

Extremely significant positive correlation $(p<0.01)$.

Interspecific association or species association refers to the spatial interconnectedness of different species. As is shown in figure 1, in all 91 species-pairs, 35 speciespairs revealed positive association, accounting for $38.46 \%$; 56 species-pairs revealed negative association, accounting for $61.54 \%$. Of the 35 species-pairs with positive association, 21 species-pairs achieved significant, extremely significant positive association, accounting for $23.08 \%$. Of the 56 species-pairs with negative association, 2 species-pairs achieved significant, extremely significant negative association, accounting for $2.20 \%$. In the test, there are more species-pairs showing negative association, indicating that the community was not stable, easy to fluctuate due to external disturbance. Most shrub species have different ecological requirements, which is consistent with the test results of the overall association between different species. The negative association of plant species-pairs reflects the mutual exclusion of species-pairs from each other, which is the result of long-term adaptation to different micro-environments and utilization of different space resources, as well as the reaction of ecological niche separation.

\section{Conclusion and Discussion}

(1)The results showed that: the aggregate distribution of Thuja koraiensis population is consistent with that of most rare plant species. As a clonal plant, Thuja koraiensis rapidly grows in the space and forms a plaque distribution pattern through the physiological integration of subfamilies in the same family. The survey found that community environment was not suitable for seed regeneration of Thuja koraiensis, asexual plant reproduction update became the main approach of natural species update, which was one of the main reasons of the aggregate distribution of Thuja koraiensis. The Thuja koraiensis population in pure forest community was mainly distributed in the abdomen and ridge of the mountain where the soil layer is thin. The entire space was occupied by Thuja koraiensis in a clustered state to resist the harmful environment.

(2)The main purpose of the interspecific association analysis of community is to explore the relationship between Thuja koraiensis population and other species and the overall direction of community succession, and thus discuss the endangered reasons and the best conditions for survival of Thuja koraiensis population. The overall association analysis of community showed that: the overall association between Thuja koraiensis community and main shrub species was significantly negative, indicating that the community is in an unstable state; there is competition among species; there are differences in environmental requirements; there is competition and mutual exclusion among species within the community.

(3)In the pure forest community, Thuja koraiensis was extremely significantly negatively correlated with Sorbus pohuashanensis $(p<0.01)$, and positively correlated with other shrub species, but did not reach a significant level. In the scattered forest community, Thuja koraiensis was positively correlated with Euonymus rehderianus, Lonicera edulis, Rubus sachalinensis, Acer tegmentosum, and negatively correlated with other species. In vegetation restoration, it is necessary to fully consider the interspecific association characteristics of plant community, and select the species that are positively associated as the recovery target. The species that are significantly negatively associated, such as Viburnum koreanum, Syringa wolfii, etc. are not suitable for allocation.

Research results of distribution pattern and interspecific association of Thuja koraiensis population provide certain theoretical basis for the breeding and protection of Thuja koraiensis, which is of great significance for the development of natural vegetation restoration and ecological reconstruction as well as biodiversity conservation.

\section{Acknowledgment}

This research was financially supported by Scientific and Technological Development Project of Jilin Province, China (Grant No.20180101017JC).

\section{References}

1. Zhang Jintun. Analysis of spatial point pattern for plant species. Acta Phytoecologica Sinica. 22, 6 (1998)

2. ShangguanTieliang, Zhang Feng. Research on the pattern and associations between dominants of the vegetation in main mountain, Shanxi province. Wuhan Botanical Research, 6, 8 (1988)

3. Guo Zhihua, Zhuo Zhengda, Chen Hao, et. Interspecific association of trees in mixed evergreen and deciduous broadleaved forest in Lushan mountain. Journal of Plant Ecology, 21, 9 (1997)

4. Huang Shineng, Li Yide, Luo ShiShou, et. Dynamics of associations between tree species in a secondary tropical montane rain forest at Jianfengling on Hainan island. Journal of Plant Ecology, 24, 6 (2000) 
5. Qi Kai, Zhang Chunyu, Hou Jihua, et. Dynamics of species diversity and interspecific associations of herbaceous plants in a Pinus Tabulaeformis forest on a sandy site in Chifeng, China. Acta Ecologica Sinica, 30, 7 (2010)

6. Meng Fanhua. Ecological Condition and Growth Regularity of Thuja koraiensis. Journal of Northeast Forestry University, 25, 3 (1997)

7. Chen Kegui, Qi Jizhong, Meng Fanhua, Wang Shouhua. Investigation on the natural resources and growth rhythm of Thuja koraiensis. Journal of Jilin Forestry Institute, 9, 7 (1993)

8. Liu Chunling, Wang Yanjun, Shi Shuanglin. Height growth regularity of Thuja koraiensis. Jinlin Forestry Science and Technology, 38, 4 (2009)

9. Jia Shichang, $\mathrm{Fu}$ Jingyang, Zhang Huanliang. Asexual reproduction technology of Thuja koraiensis. Jilin Forestry Technology, 2, 2 (1992)

10. Yin Hang, Zhao Ying, Cui Kaifeng, Liu Lijie, Yu Changbao, Chen Qinghong, Dai Yuhong, Zhao Wei. Asexual Reproducition Technique of Thuja koraiensis Nakai. Chinese Wild Plant Resources, 32, 2 (2013)

11. Wang Zhengfeng, An Shuqing, Zhu Xuelei. Distribution pattern of tree populations in tropical forest and comparison of its study methods. Chin J App Ecol, 9, 6 (1998)

12. Xie Zongqiang, Chen Weilie, Liu Zhiyu, et. Spatial distribution pattern of Cathaya argyrophylla population. Acta Bot Sin, 41, 7 (1999)

13. Zhang Jintun. The Methods of Quantitative Ecology for Vegetation. Beijing: China Science and Technology Press, 12 (1995)

14. Huo Hong, Feng Qi, Su Yonghong, et. Interspecific Relationship and Niche Analysis on Phytocoenosium in the Ejina Oasis. Journal of Desert Research, 33, 7 (2013)

15. Jin Hui, Yin Hang, Li jiangnan, et. Interspecific Association analysis of species in shrub Layer of Rhododendron chrysanthum Community in Alpine Tundra of Changbai Mountain. Journal of Beihua University,

15,

6

(2014) 